\title{
Philosophical Foundations of Environmental Policy Analysis: Can Critical Realism Bridge the Neopositivist/Interpretivist Divide?
}

Andrew Pearce Carter

andrew.pearce.carter@gmail.com

${ }^{*}$ Abess Center for Ecosystem Science and Policy, University of Miami
+ Current affiliation: Center for Conservation Innovation, Defenders of Wildlife
${ }^{\ddagger}$ Current affiliation: Affiliate Faculty, Department of Environmental Science and Policy, George Mason University

Abstract: Traditional environmental policy analysis has followed a neopositivist epistemological frame, using the natural sciences as a template as to how social-ecological problems can be analyzed. Such approaches to policy analysis have been caught up in the same crisis as the social sciences have in general: an overarching failure to create a predictive science of society or to consistently provide solutions to social problems. This has led some policy researchers to align with the interpretivist turn, which has had its own drawbacks. In this review I summarize the historical development and main tenets of both approaches, examining their advantages and disadvantages. I then review an alternative epistemological approach to social science, critical realism, which combines an ontological realism with an epistemological relativism, a focus on elucidating causal mechanisms in the social-ecological systems studied, an approach that may be particularly suited for analyzing the complex social-ecological systems studied in environmental policy analysis. 


\section{Overview}

Environmental policy analysis, whether prescriptive or descriptive, remains plagued with significant failures; we are, generally, poor at prescribing human interventions that can significantly mitigate environmental problems, particularly those "wicked" problems (Rittel and Webber, 1973) that defy easy analysis or solution. Environmental policy typically relates to two different types of goals: pollution control and natural resource management. Both implicate complex and interconnecting social and ecological systems that defy easy analysis or solution, and cut across multiple levels of organization both physically and socially - local, regional, national, and international. Designing and implementing (or even analyzing after-the-fact) a given environmental policy effectively often requires not only an in-depth understanding of human behavior and institutions, but also a similarly complex understanding of physical phenomena. Layered upon these uncertainties are the multitude of political and ideological lenses which have seen debates over environmental policy become some of the most contentious political debates on the public stage.

While environmental policy analysts do carry out some their work in the natural sciences, the unified discipline is fundamentally a social science in practice because its primary aims are to describe and prescribe institutions that govern how societies engage with their natural surroundings. As such, environmental policy analysis as a practice also necessarily becomes caught up in recurring debates over social science epistemology, including the fundamental question of whether the researcher's understanding of the social behavior studied can best be captured through the methodological templates of the natural sciences, i.e., hypotheticodeductive reasoning and empirical verification (or falsification) of theories, or through more interpretivist methods that focus on the social construction of reality and meaning, and how 
problems are defined and communicated by the stakeholders encountering them. Traditionally, environmental policy analysts have largely followed the former approach. Under this paradigm, and as implemented in the modern policy analysis field as practiced by most government and many academic analysts, the practitioner's job is to serve as a "neutral" expert who can analyze policy options and select or help select the optimal choice given the policy goals. Such methods tend to be focused on quantitative data and statistical analyses, with the presumption that such methods can be generalized across different times and places to analyze similar issues. In the policy analysis context, this has been approach has been referred to alternately (though typically by its critics) as "traditional policy analysis" (Shulock, 1999), the rationality project (Stone, 2002, p. 7), or the technocratic approach (Jasanoff 1990, p. vii). Following Fischer (1998) I refer to it generally as neopositivism, capturing its traditional

Though neopositivist approaches to policy analysis are still widely used, they have been caught up in the same crisis as the social sciences have in general: an overarching failure to create a predictive science of society or to consistently provide effective solutions to social problems (e.g. Boguslaw, 1979; Fischer, 1998; Rittel and Webber, 1973). Analysts can describe but rarely accurately predict, and attempts to do so through public policy prescriptions frequently fail, either through their own inherent flaws or because they are either ignored or changed by political actors in ways that reduce their effectiveness, often intentionally.

In the face of this failure, and objecting to the neopositivist approach as not only methodologically flawed but also morally suspect, a number of policy researchers have instead aligned themselves with the interpretivist turn in the social sciences and humanities. Drawing on work done over the last several decades of the $20^{\text {th }}$ century in fields such as Science and Technology Studies (STS) and cultural anthropology, proponents of interpretivism not only see 
social phenomena as fundamentally different from physical phenomena-and thus requiring a different way of examining them-but also inextricably linked with questions of value that cannot be captured adequately by neopositivist investigation. Extreme versions of this often see neopositivism as unsuitable for both science and social science. " "Interpretivism" covers a significant variety of research theories and methods, ranging from the hermeneutical to critical, but it shares a common set of themes: A focus on the construction and communication of meanings, qualitative research methodologies, a suspicion of naturalistic inquiry, and a greater willingness for the social scientist to explicitly engage with normative questions.

This article has three goals: (1) Review the two major competing philosophical approaches to environmental policy analysis, neopositivism and interpretivism, situating each in their philosophical and historical context; (2) Examine an alternate philosophical foundation to environmental policy analyses, critical realism, a meta-theory that seeks to engage with a naturalist reality while recognizing the epistemological limitations of knowing that reality; and (3) Conclude with some examples of what a critical realist approach to environmental policy analysis might look like, and how such an approach would differ from primarily neopositivist or interpretivist approaches. Some of the examples set forth here to illustrate different approaches are taken primarily from environmental policy in the United States, particularly at the federal level, though the philosophical debates discussed are global in scale and not restricted to a specific political or cultural milieu. A significant amount of work has already been written on the debate between neopositivist and interpretivist approaches to policy analysis, as well as on the

\footnotetext{
${ }^{1}$ Such beliefs are common in postmodernist/post-structuralist and critical research programs. These paradigms are sometimes distinguished from interpretivism, though the boundaries between them and more "traditional" interpretivist approaches are often blurred or amorphous, particularly in applied social science fields like policy analysis. For the purposes of this article, I group postmodern and critical approaches to policy under the interpretivist umbrella; to the extent that extreme relativist versions of those paradigms do not qualify as "interpretivist," they are not typically relevant to environmental policy analysis as a distinct field.
} 
critical realist alternative to those approaches. Here I attempt to offer an original contribution to the literature by collecting, condensing, and analyzing both subjects in the specific context of environmental policy analysis as a field.

\section{Neopositivism and the Birth of the "Policy Scientist"}

The $20^{\text {th }}$ century saw the convergence of unprecedented changes to the physical and social environment. Two centuries of industrial growth and scientific development had both fundamentally reshaped the physical environment at the same time it provided resources for rapid population growth across the world. Improving transportation networks led to increased economic ties between often far-flung areas of the earth. Concomitant with the rapid spread of industrialization has been growth in the size and responsibility of national and local governments as increasingly complex and spatially expanding economic and transportation infrastructures, including the massive mobilization of both human beings and industrial capacity needed for the two world wars.

The growing success and prestige of the natural sciences and cognate engineering fields inspired social thinkers to mimic their methods when attempting to derive scientific "laws" regarding social behavior that could be applied to an increasingly more complex social sphere. While deductive approaches to problem-solving in the natural sciences had largely driven the scientific revolution, prior to the late $19^{\text {th }}$ century approaches to analyzing social institutions had remained largely the province of philosophers. However, by the late 1900s a subsequent generation of social scientists, inspired by the synergetic success of the rapidly developing science and technology of the time, proposed a new course for those studying the social. The founder of this "scientific" approach to social science, Auguste Comte ([1848]1865, [1896]2000), proposed that both the natural sciences and the "human" sciences shared a 
positivist epistemological framework, an assumption that was seized upon by many in the rapidly expanding social sciences. As Rabinow and Sullivan put it $(1979,1)$, “[a]s long as there has been a social science, the expectation has been that it would turn from its humanistic infancy to the maturity of hard science, thereby leaving behind its dependence on value, judgment, and individual insight."

Fischer (1998, pp. 143-44) provides a useful definition of the neopositivist approach as it became expressed in the policy analysis field as "the modern-day embellishments of 'positivism'," incorporating two main prongs: (1) it assumes knowledge of social phenomena can only be reliably gained through following traditional natural or formal "scientific" methods of "empirical falsification [or verification] through objective hypothesis testing," with the goal of generating empirical explanations of human behavior that can be applied across cultural and historical contexts; and (2) it enforces a "rigorous separation of facts and values," where the investigator sees her job solely as establishing those empirically derived facts without any "normative context or implications." Normative aims, to the traditional neopositivist policy analysis, are to be decided by political actors such as elected officials. In terms of environmental health risks, for example, the neopositivist policy analysts' job is to quantify those risks, then create or select the most effective means to ameliorate that risk based on the normative instructions given by the normatively empowered policymaker or politician - whether it is to reduce the chance of harm to a specific probability, or to compare the costs and benefits associated with harm reduction strategies.

Both prongs of the neopositivist approach are heavily influenced by the work of the philosopher David Hume. Hume argued that to establish that one event caused another, the observer could only infer such a causal relationship from observation of "constant conjunction" 
between the possible cause and the possible effect (1748, p. 148). Even then, according to Hume, there is no way to conclusively demonstrate matters of fact because at some point that constant conjunction must fail. Philosophers of science would refine the Humean proposal, most famously Karl Popper who extended and formalized the thesis by arguing that scientific discovery could in fact only be carried out through falsification of hypotheses, with the ones that survive such falsification accepted as provisionally but never conclusively true (Popper, 1959). Hume was also influential in establishing that scientific (or any other kind) of factual inquiry could not discover moral truths, or that you could not go from "is" to "ought" ([1738] 2007, p. 302).

In the United States, the positivist European sociology was adapted along with a burgeoning field of "scientific management" theories as well as parallel movements developed in the private sector to increase industrial efficiency (Waldo, 2006, pp. 40, 47; Stone, 2002, p. 7). In the political sphere, Progressive Era thinkers and politicians sought to bring about good (and efficient) government by shifting policymaking authority from frequently corrupt elected bodies to putatively neutral professional experts (Waldo, 2006, p. 40; Stone, 2002, p. 7).

As the regulatory state grew through the 20th century, the quantitative social sciences and "scientific management" practices of industry and governments converged into a syncretic, specialized field of "policy science." Its early theorists, most prominently the political scientist Harold Lasswell, articulated a "policy science" paradigm that saw the policy analyst's job as establishing the "empirical validity" of policy options (Lasswell, 1971, p. 24) through a process modeled on the positivist assumptions underlying the natural sciences.

There are two central assumptions of most neopositivist policy analysts that fundamentally direct how they practice. The first is that policy is-or at least should be-follow a "policy cycle," where policy development is done through a series of discrete stages that separate 
factual determinations (to be made by the "policy scientist") from value determinations (to be made by political actors, presumably democratically elected ones). The "policy cycle" idea is based on both the neopositivist search for "covering laws" that can be employed universally, as well as its separation of factual determination from value judgment. The second is the rationalist belief that individuals take actions consistent with maximizing their own gains; adopted largely from economics, this "rational-actor" model drives a significant amount of policy decisionmaking, and is frequently expressed through another policy tool out of economics, cost-benefit analysis.

The primacy of neopositivism in governmental policymaking is not particularly surprising; politicians tend to want a definitive answer to policy questions defensible with quantitative data. In the United States especially, another factor driving the neopositivist dominance may be the fact that many non-positivist theoretical approaches draw from social science traditions that are politically fraught in that country, where relativist forms of inquiry have historically been viewed with suspicion, at least until recently, by those on the political right. Furthermore, incorporating diverse stakeholder meanings into environmental policy discussions can also be counterproductive for regulated industries that oftentimes wield outsized influence in policy debates, and are often able to leverage significant technical expertise to prepare putatively "objective" analyses of policy options that benefit those industries particularly when rulemaking authority is held by politicians skeptical of environmental regulations to begin with (Layzer, 2012; Mintz, 2012). Disciplinary factors also play a large role; environmental policy analysis is frequently conducted by engineers, natural scientists, and economists who are more comfortable with using quantitative data to probe naturalistic causal mechanisms than they are with deconstructing stakeholder meanings and interests, and who tend 
to see their factual inquiries as free (ideally) from political concerns that may impact those findings. Furthermore, and particularly important for environmental policy analysts, the neopositivist approach can in some cases be built into law and policy (Ascher, Steelman and Healy, 2011). In United States federal courts, for example, the admissibility of scientific evidence is determined by the Court. In Daubert v. Merrell the United States Supreme Court held that in determining admissibility a "key question to be answered . . . will be whether it can be (and has been) tested," and explicitly quoted Karl Popper for the proposition that "[t]he criterion of the scientific status of a theory is its falsifiability, or refutability, or testability." (Daubert v. Merrell Dow Pharmaceuticals 1993, p. 593).

\section{The Interpretivist Turn}

While it remained the dominant approach in the social sciences generally up until the second half of the twentieth century, neopositivist approaches to examining human phenomena and prescribing human actions failed in large part to fulfill Comte's vision of precision and reliability. Though the positivist approaches to policy analysis are still widely used as an evaluation tool, particularly in governmental agencies, and taught to undergraduate public policy students, such an approach has been caught up in the same crisis as other social sciences: an overarching failure to create a predictive science of society or consistently provide effective solutions to social problems (Boguslaw, 1979; Fischer, 1998; Rittel and Webber, 1973).

Furthermore, the sociological critiques of science developed after Kuhn's groundbreaking 1962 Structure of Scientific Revolutions also called into doubt many of the epistemological assumptions of the natural sciences themselves, further weakening the argument that the natural sciences should serve as a normative ideal for the social ones (Kuhn, 2012; Sismondo, 2008). Science and cognate technical fields held a privileged position since the Enlightenment; Comte 
saw natural science as the ideal template for the social sciences precisely because of that apparent success. For Kuhn and his successors, rather than be an objective and continuous refinement of empirically-based models that are tested objectively against the natural world, science is a social process in which the scientist is caught up in the scientific paradigm in which she works; in the Kuhnian view, scientists debating opposing theories arguing for different theories "see different things when they look from the same point in the same direction." (Kuhn, 2012, p. 150).

Kuhn's work inspired a revolution in the sociological and historical study of science and contributed to the formation of the field of Science and Technology Studies (STS) ${ }^{2}$ which explores, among other things, the social construction of science and scientific practice. That field in turn helped create a skeptical attitude towards traditional scientific methods across a wide swathe of other social science practitioners, including public policy researchers: If neopositivism did not even produce what its proponents claimed it did for the natural sciences, how could it do so for the social ones? For the environmental policy analyst called on to investigate both natural and social systems, the STS project complicates both analyses.

In addition to the perceived epistemological shortcomings in the traditional social sciences in general, critics have attacked it for divorcing ethical judgments from "policy science" and privileging expert decision-making, questions of value can be recharacterized as scientific or technical questions and thus removed from democratic control (Amy, 1984; Durning, 1999; Hawkesworth, 1988, p. 6; Jasanoff, 1990, p. 229). Indeed, not only can those questions of value be redefined, but even hidden - as Daniel Sarewitz notes, the "risk for society . . comes from pushing the political into the black box of the technical, thus making it invisible to democratic

\footnotetext{
${ }^{2}$ Also referred to as Science, Technology and Society by some practitioners.
} 
actors." (Sarewitz, 2016, p. vi). This is especially true for what the physicist Alvin Weinberg (1974, p. 209) famously referred to as "trans-scientific questions," or questions of fact that be asked of, but not answered by, science due to factors such as logistical impossibility or because they cannot be separated from questions of value.

Extensive historic accounts support such arguments; the perceived strength of natural science methodology also increased its value in policy debates as a rhetorical weapon: "Because science is highly valued as a source of reliable information, disputants look to science to help legitimate their interests" (Sarewitz, 2000, p. 83). The historical record is replete with examples: Sheila Jasanoff, for example, has detailed how environmental policy participants often try to gain control of debate by characterizing key issues as either policy or science when they are at the boundary at both (Jasanoff, 1990). Similarly, examining the historical development of United States federal environmental regulatory apparatus since, Judith Layzer found much of putatively "scientific" debate existed instead as "struggles to define problems and characterize solutions within a rhetorical and institutional context" (Layzer, 2012, p. 11).

The perceived shortcomings of the neopositivist project in the social sciences generally has led to an explosion of theories and methods to explore human behavior that reject positivism, mostly under a postpositivist umbrella focused not on quantitative analysis or the derivation of universal social laws, and more on the "interpretation" of the subjective human meanings of those involved in, or impacted by, policy (or proposed policy). Applied to policy analysis, this interpretivist approach engages more explicitly with stakeholder values and systems of meaning, with its "central question ... How is the policy issue being framed by the various parties to the debate?" (Yanow, 2000, p. 11). The interpretive turn in social science necessarily repudiates both prongs of the neopositivist project. Rather than conceive of social phenomena as amenable to the 
same investigative methods as physical phenomena, the interpretivists see such phenomena as driven largely by - and existing in - human meaning, values, desires, and discourses, or the "web of language, symbol, and institutions that constitut[e] signification." (Rabinow \& Sullivan, 1979, p. 4).

\section{The State of the Environmental Policy Field}

This neopositivist-interpretivist divide in environmental policy approaches leaves two overall approaches that offer insight into policy descriptions and prescriptions that exist in tension. The neopositivist framework provides, on its surface, quantitative rigor of the natural sciences, which may become more useful in light of computational advances, the increasing availability of large datasets, and insights from recent - and fruitful - experimental research into judgment and decision-making (e.g., Kahneman, 2011). At least in theory, this approach is more scalable and amenable to comparative analyses. However, it also tends to reduce complex social and natural phenomena to simple models or equations that are parsimonious but unreflective of social-ecological complexities, and susceptible to politicization. And when faced with environmental policy failures, neopositivist approaches therefore tend to focus on improving either the tools of environmental policy analysis (e.g., models, monitoring methods, or statistical methods) or improving the policy process itself in a way that increases incorporation of scientific and technical expertise (e.g., increased reliance on the "best available science"). Those utilizing this approach "have not abandoned the hope that the instruments of perfectibility can be perfected" (Rittel \& Webber, 1973, p. 158). ${ }^{3}$

\footnotetext{
${ }^{3}$ For example, when Peter House and Roger Shull, two government scientists with collective decades of experience in policy analysis at the EPA, attempted to summarize the field in their 1991 book, The Practice of Policy Analysis: Forty Years of Art \& Technology, they divide the history of Federal "policy analysis" into eras based on the types of quantitative models used-and propose that past limitations in the value of those models may be remedied by increasing computing power. Reflecting the neopositivist discomfort with questions of values, they suggest issues "dominated by moral perspectives" are often not amenable to policy analysis (House \& Shull, 1991, p. 25).
} 
The interpretivist framework gives the environmental policy analyst improved tools to examine how individuals are involved in or impacted by policy decisions, and to cast a more critical eye on the political and ideological interests and strategies used to direct the policy process. This has allowed interpretivist-minded analysts to draw out value judgments from putatively "value-neutral" policy choices and show how they influence policy decisions. However, as too often practiced, the moral dimensions of policy choices remain caught in the center of the interpretivist project, defined by Yanow $(2000,5)$ as the "presupposition that we live in a social world characterized by the possibilities of multiple interpretations." As a result, interpretivists frequently articulate stakeholder values without evaluating their rationales. Furthermore, an overly interpretivist, critical focus on the meaning has often led to ignoring the extradiscursive reality of the physical world, with scientific research often cast as a mostly - or even completely - social activity that displaces alternate and equally valid forms of knowledge. An environmental policy to reduce public health risks of a contaminant is only successful if it in fact reduces that health risk, and the measures taken to do so do not cause greater damage elsewhere, and not simply if the policy has wide approval or public acclaim.

However, mirroring neopositivists, many interpretivists see policy failures as tending to arise from a failure to be interpretivist enough - in other words, properly understand and incorporate stakeholder understandings into policy development. They therefore urge increased focus on understanding and incorporating impacted stakeholders in environmental policy decisions, often calling for an "argumentative," "deliberative," or "discursive" approach to policy analysis and development (Fischer and Gottweis 2012; Hajer and Wagenaar 2003; Fischer 2003). By embracing rather than trying to exclude rhetorical and discursive contention, these theorists seek to create procedures that would make such debates transparent and subject to 
democratic control and procedural equity. Such approaches take different forms, but are often modeled on the idea of argumentation undertaken by legal arguments in the courtroom, incorporating analogues of rules of evidence, and seeking to "move the policy evaluation process towards a judicious mix of pragmatism and rigour" (Fischer 2003, 187). Is embracing an adversarial process of democratic engagement by stakeholders, constrained by fair and transparent inclusion, a model for environmental policy moving forward? Historical evidence suggests that in many cases, no. Certainly anyone who has practiced law knows that the outcomes of court cases frequently lack either pragmatism or rigor, evidentiary rules are often subject to abuse or manipulation, and economic disparities between litigants are too often dispositive of cases. Jasanoff $(1990,246)$ objects to submitting such policy disputes to adversarial processes, arguing that they "promote[] an unproductive deconstruction of science and fosters the appearance of capture." An "argumentative" development process also appears to suffer the same problem as the focus of interpretivist approaches generally: it tends to measure success in terms of collective stakeholder satisfaction, a defensible goal when satisfaction is the main or only goal, as in Yanow's interpretive analysis of public satisfaction with a local community center $(2000,33)$, but not when the protection of health or safety is dependent on physical phenomena that cannot be adjudicated or agreed away.

The two paradigms exist in tension. Generalizable theories based on sociological, economic, and psychological phenomena arise out of the neopositivist project before frequently falling by the wayside as they prove inadequate at predicting human behavior or adequately addressing environmental problems (e.g. Rittel and Webber, 1972; Shulock, 1999). Interpretivists can dismantle neopositivist assumptions that social and natural phenomena can be 
objectively understood and predicted by a neutral researcher, but a focus on meaning and discourse frequently leaves little room to predict or prescribe policy.

So given these two dominant paradigms, and operating under the almost inescapable conclusion that environmental policy has been less than successful, how should a policy analyst proceed? Addressing the "ongoing quarrel" between positivists and interpretivists, Gorski (2013, 660-61) cautions that it "did not prevent social scientists from producing valuable research ... [and] [w]e have learned to glide through social reality with some skill.” But according to Gorski, this is only because social researchers "have unlearned" what they were taught and passed the "tacit knowledge of good research practice on to others" $(2013,661)$. Similarly, environmental policy analysts on both sides of the divide have done important, and occasionally successful work-in the sense that they accomplish many or all of their objectives-through a pragmatic engagement with environmental problems in their particular social, scientific, and geographical contexts. In recent decades government-based environmental policy analysts have become more accepting of approaches that accomplish this, such as improved stakeholder involvement, collaboration, and adaptive management.

Academic policy analysts and theorists have often been on the forward edge of these developments, developing elaborate methods that go beyond the policy cycle concept and seek to more effectively navigate the tensions between technocracy and democracy, developing critiques and proposing solutions to retain scientific rigor while increasing transparency and public involvement in policy (e.g. Ascher, Steelman and Healy 2011; Guston 2013). Such approaches are, of course, easier said than done. Ascher, Steelman and Healy $(2011,190)$ propose that reforming environmental policy institutions requires a "hybrid of formal science, local knowledge, and public preferences," but figuring out exactly how to arrange that hybrid is 
difficult. Local knowledge may be valuable for policy decision-making, but contra some extreme relativist versions of interpretivist research, it seems unwise to incorporate its factual conclusions into policymaking simply because it is local knowledge (and thus representative of stakeholder meaning). Harry Collins and Robert Evans refer to this as the "Problem of Extension" (2002, 237): Even accepting STS critiques of scientific claims to objective truth, and the need to incorporate democracy into policy science discussions, policymakers are still left with the question "How far should participation in technical decision-making extend?"

The greater the level of hybridity-the more an environmental problem implicates a complex mixture of natural and social phenomena as well as questions of value-the greater the chance that policy analyses and prescriptions fall within the neopositivist-interpretivist gap. While there are, of course, no easy answers, a different epistemological approach may help in bridging this divide.

\section{Critical Realism as an Alternate Philosophical Framework}

Just as "neopositivism" and "interpretivism" as used here encompass broad groupings of theoretical and methodological approaches to policy analysis, "critical realism" has various different forms and practices, though here I refer specifically to the modern intellectual movement founded by the British philosopher Roy Bhaskar. ${ }^{4}$ A full philosophical treatment of critical realism is well beyond the scope of this article, though I will briefly summarize some of the primary principles that Bhaskar initially developed. ${ }^{5}$ These initial principles and their implication for practice have been largely (though not universally) retained by other critical

\footnotetext{
${ }^{4}$ This should be distinguished from the identically-named philosophical movement of the early $20^{\text {th }}$ century, epitomized by such thinkers as Roy Wood Sellars, Maurice Mandelbaum and George Santayana, though there are some common threads between both movements (Verstegen, 2009).

${ }^{5}$ For a more comprehensive introduction to critical realism, see Archer, Bhaskar, Collier, Lawson and Norrie (1998), Collier (1994), and Sayer (2000).
} 
realist scholars as the core components of the metatheory, and which may have special import for environmental policy analysis. ${ }^{6}$ Bhaskar's later work has generally not had the same impact as his earlier work, and as a result modern critical realism in the social sciences tends to follow that earlier work, as augmented and extended by other theorists (e.g. Gorski 2013; Sayer 2000, p. $170)^{7}$

\section{Roy Bhaskar and the Development of Critical Realism}

The beginning of critical realism dates largely from 1974, when Bhaskar published $A$ Realist Theory of Science, in which he proposed a "comprehensive alternative to the positivism that has usurped the title of science" (Bhaskar [1974] 2008, 1). Like many of his contemporaries, Bhaskar was skeptical of the positivist epistemological tradition in science, but he also did not see any of the alternative theories of the time as an adequate replacement epistemology for the sciences. While it was clear to him that the positivist principles were unsustainable, interpretivist approaches (he referred to them as hermeneutic) were also problematic; he thought both approaches suffered from what he referred to as the "epistemic fallacy" - the reduction to or analysis of the world and the things in it to statements about knowledge (Bhaskar [1974] 2008, 26).

To avoid this epistemic fallacy, Bhaskar argued for a re-engagement with ontology, or the study of what exists in reality, unmediated by the human perception or conception of it. Traditional epistemological questions such as "How can we trust our senses?" or "How accurately does our knowledge represent actual reality?" have been a subject of debate for thousands of years. Bhaskar inverted that question, approaching it from an ontological

\footnotetext{
${ }^{6}$ A number of other modern thinkers have developed similarly realist alternatives (e.g., Hacking, 1983; Putnam, 1981).

${ }^{7}$ Natural scientists have generally paid little attention to Bhaskar or most philosophers of science, though many have engaged critically to some extent with Popper and Kuhn. (e.g., Sokal \& Bricmont, 1997).
} 
perspective, asking: "What must the world be like for knowledge of the world to be possible?" (Bhaskar, 2008, p. 23). Focusing on the practice of science in the real world rather than as abstract "observation," Bhaskar reasoned that scientific experimentation presupposed both the existence of an actual reality with structures and causal mechanisms that existed whether we perceived them or not. Rejecting the Humean position that causation could only be explained in terms of "constant conjunctions of events," Bhaskar reasoned that such causal reasoning could only hold true in closed systems (like scientific experiments) (Bhaskar, 2008, p. 134). In other words, that a meteorologist found that at a specific time a sudden decrease in air temperature did not result in rain does not mean that decreasing temperatures cannot cause rain, but simply that some other causal mechanisms (whether detected or not) counteracted that tendency.

Rather than a "flat" reality populated by phenomena and our observations of them, Bhaskar proposed instead a stratified reality, one that had to be distinguished from our knowledge of it. He did this by first dividing "objects of knowledge" into the intransitive and the transitive. Transitive objects of knowledge are, according to Bhaskar, "the artificial objects fashioned into items of knowledge by the science of the day" (Bhaskar, 2008, p. 11). These are the products of scientific inquiry, things like facts, theories, models, and methods. Intransitive objects of knowledge, on the other hand, are the unchanging characteristics of the real world, unaffected by our interpretation or understanding of it. Bhaskar then created a further layer of differentiation between "three overlapping domains of reality": the real, the actual, and the empirical (Bhaskar, 2008, p. 46). The real consisted of everything that exists, whether social or natural, and including mechanisms, powers, and relations, whether they have been expressed or not (or observed or not). The actual consists of those things in the real that have been expressed. The empirical makes up a narrowed subset of the actual, consisting of expressions that have been 
observed. From these starting points, he established the concept of emergence: Strata of reality are dependent on a lower level, but irreducible to it (Bhaskar, 2008, pp. 160-61). Causal mechanisms in one strata cannot explain a more advanced one; the common example is knowing the structure and dynamics of hydrogen and oxygen atoms cannot allow one to adequately explain the emergent properties of water (e.g. fluid mechanics).

It was in Bhaskar's second work, The Possibility of Naturalism, in which he placed the social sciences into the same realist framework, work that would ultimately spark a cohesive realist movement among philosophers and social scientists. Bhaskar did this by asking a question similar to the one on which he premised his realist theory of science: "What properties do societies possess that might make them possible objects of knowledge of us?" (Bhaskar, 2015, p. 31). He answered the question similarly, but not identically, to the analogous question he asked about how we could understand the natural world; as with his epistemological approach to scientific inquiry, Bhaskar saw the social scientist's job as seeking to articulate the causative mechanisms of social phenomena rather than simply follow a neopositivist search for constant conjunctions, with the understanding that like many natural systems, social systems were open. Social phenomena, like natural phenomena, were ontologically stratified and marked by emergent levels that were dependent on more basic levels, but irreducible to them. Just like the behavior of water could not be explained in terms of the structures of hydrogen and oxygen atoms, societies could not be explained in terms of the behavior of individual actors.

For Bhaskar, however, the social world had a large caveat: Social structures, unlike natural ones, could not exist outside the actions of human actors. That did not mean, however, that such social structures and mechanisms did not have an independent existence; Bhaskar explicitly rejects Karl Popper's maxim that "all social phenomena, and especially the functioning 
of social institutions, should be understood as resulting from the decisions etc. of human individuals" (as cited in Bhaskar, 1998, p. 208). But he also rejects the opposing view represented by structuralists like Emile Durkheim (and taken up in the past couple of decades by numerous post-structuralists and postmodernists) that individual human behavior was largely driven by the social structures of which they were a part. Proposing what he called a "transformational mode of social action," Bhaskar theorizes that the existence of social institutions prior to human interaction with them rendered their study possible; just as with natural scientific inquiry, critical realist social scientists could examine social behavior in terms of causal mechanisms involved in an intransitive social system that could be explained in terms of causal mechanisms and emergent properties. Critiquing the second neopositivist prong of the fact-value dichotomy, Bhaskar suggested that factual investigation could have a normative effect in the form of an "emancipatory potential ... contingent upon, and entirely a consequence of, its contextual explanatory power" (Bhaskar, 2015, p. 32). Better explanations of causal mechanisms can free the members of society from illusions that can hinder wellbeing.

Bhaskar's influence on practicing natural scientists was minimal, but with philosophers and social scientists his theories received far more attention. Though much of the postmodernist/poststructuralist turn in social science came after, Bhaskar's work generated powerful critiques of that turn (e.g. Sayer, 2000).

\section{Critical Realism: Implications for the Environmental Policy Analyst}

The critical realist approach combines for both the natural and social sciences what Bhaskar referred to as the "'holy trinity' of critical realism" (Bhaskar 2010, p. 1):

(1) Ontological realism: much of reality exists outside our awareness, observation, or knowledge of it; 
(2) Epistemological relativism: any understanding of that reality we gain is fallible and always conditioned by our historical, social, and cultural context; and

(3) Judgmental rationality: despite this fallibility, there are logical criteria for distinguishing between better and worse accounts of that reality.

For the environmental policy analyst analyzing natural, social, and hybrid phenomena, these three foundations offer if not a well-specified theoretical or methodological framework, a general guideline to choose such frameworks, and a mandate to focus her research on understanding causal mechanisms and the emergence of phenomena from a multiplicity of those mechanisms.

While this may seem uncontroversial, particularly to the policy analyst, the critical realist position goes against centuries of positivist assumptions and methods in both the social and natural sciences that are used in policy analysis. The Humean search for constant conjunctions is perhaps most strongly reified in correlational statistical methods like regression models, methods which lie at the core at both natural and social scientific fields heavily invested in the environmental policy domain, as well as hypothesis testing. As Gorski (2013, p. 663) phrased it in regards to sociology, "[t]he ghost of logical positivism still haunts contemporary discussions of methodology." Furthermore, given the multiplicity of potential causal mechanisms in open systems (like most social-ecological systems), analysis often requires "a diachronic explanatory reduction', that is, a reconstruction of the historical processes of their formation out of 'simpler' things." (Bhaskar 2015, p. 39). For the environmental researcher, a static analysis of a situation without understanding how that situation arose limits understanding. 


\section{What Does a Critical Realist Environmental Policy Analysis Look Like?}

Even accepting critical realism would serve as the philosophical foundation for a theory of an environmental policy analysis, two questions arise: First, how far should analysts openly engage with its philosophy when developing or applying their work? Second, what would a critical realist environmental policy analysis actually look like?

There have been numerous arguments made for the importance of theory in policy analysis, both theoretical and applied (e.g. Cairney, 2013; Colebatch, 2005). Indeed, drawing too sharp a distinction between theory and method seems untenable; as Sayer (2000, p. 122) notes, "observation is not theory-neutral but theory-laden, and . . . theory does not merely 'order facts' but makes claims about the nature of its object." Thomas Kuhn formulates it as "[p]aradigms determine large areas of experience at the same time" (Kuhn 2012, p. 128). The study of policy is no exception to this maxim: The analyst cannot do her job without some preconceived epistemological stance as to the validity of the processes she is using to obtain knowledge of the object of her study whether that object be social, biophysical, or a "hybrid" (Latour, 1993, p. 1) of both. Ignoring theory simply risks moving it to the researcher's unconscious, where it can unreflexively impact her work while preventing self-examination.

This does not mean the analyst need actively reconstruct explicit epistemological grounds for each analysis from the ground up: an initial engagement and agreement with a philosophical framework like critical realism can allow the analyst to devise relatively straightforward guiding principles to be a foundation for the analyst's subsequent work-even if the exact steps which she took to come to that foundation later escape her memory. Both prongs of critical realism, addressing both the natural sciences and social sciences, offer that comprehensive metatheoretical foundation for environmental policy analysis. Indeed, where the environmental 
policy analyst must frequently move between natural scientific questions (e.g., how does a certain contaminant move through the environment?) and social scientific questions (e.g., what social institutions would be effective means of reducing the risk of that contaminant?), critical realism offers a comprehensive metatheory: an epistemological base upon which appropriate theoretical and methodological approaches can be built.

Accepting, at least going forward, that engagement with critical realism will enhance the environmental policy analysis process, what would that process look like? Critical realism has often been criticized for its lack of specificity, but it intentionally does not mandate a specific theoretical or methodological approach, instead urging that the nature of a stratified, differentiated reality requires pluralist modes of inquiry. While critical realism does not tell us which types we must use, it does to some extent tell us what not to use. Purely neopositivist theories or methods that expressly disavow inquiry into the unobservable-like the behaviorist school that dominated American experimental psychology for most of the $20^{\text {th }}$ Century-should not be used, at least in isolation. If such methods are used their limitations should be openly acknowledged and supplemented by an interdisciplinary mixture of methods better able to collectively elucidate causal structures. For example, a general linear model that associates a specific adverse environmental health impact with certain demographic factors should not be the sole driver of which policy intervention is appropriate. The critically engaged analyst should examine why members of that community are disparately impacted by an environmental hazard to lend insight to remedial policy prescriptions.

On the other end of the spectrum, some postmodernist approaches that seek to delegitimize any statements about reality are incompatible with a critical realist approach; while postmodern critical methods, such as deconstruction, can assist the policy theorist in re- 
appraising previously unconscious assumptions and biases, they should not be taken to the ultimate postmodernist conclusion of purely relativist, fractured modes of knowing.

Deconstruction without construction can ultimately results in what Andrew Sayer has referred to as "defeatist postmodernism," or the erasure of the distinction between true and false (Sayer, 2000, pp. 67-68).

Archer et al. (2016) propose that critical realism can "provide a warrant for a historical sociology that uses small-N case comparative analysis to reconstruct the complex, contingent, and conjunctural nature of causality" - such a research program for environmental policy analysis would exist in direct contradiction of the "policy cycle," and be far closer to the interpretivist policy analysis program set forth by Yanow (2000) and others. Environmental policy under this warrant would seek to, among other things, place environmental problems in their unique historical context. However, such a case study-focused analysis in a critical realist frame would always keep in mind the biophysical existence of environmental problems and how social institutions interact with them, and have interacted with them historically.

From the policy researcher's perspective, critical realism is neither revolutionary nor a panacea for the central problems of the environmental policy field. Not all critical realist insights may prove useful to environmental policy analysis, and those that do would likely result in evolutionary as opposed to revolutionary change to the analysis and prescription of human institutions to climate change. Furthermore, analyses of real-world public policy are often constrained in ways that other natural and social scientific analyses are not, in that often the policy analyst's directive from her employer is to follow a narrowly prescribed method using designated datasets and analytical methods. When the analyst has the freedom to use it, critical realism has provided value to environmental policy-related research. Forsyth (2001, p. 2), for 
example, proposes that "[critical] realist political ecology ... seek[s] to . . reconstruct new and more effective science for environmental policy that is both biophysically more accurate than existing conceptions, and socially more just."

In order to extend a critical realist epistemology and ontology to actual methodology, I discuss possible critical realist approaches to specific aspects of environmental policy research, including both how substantive policy analysis might be done, as well as the procedural process of environmental policy evaluation, development, and intervention. Below I explore three areas in which critical realism can impact how environmental policy analysis is performed,

specifically: (1) interdisciplinarity; (2) defining environmental problems; and (3) environmental justice. The first two involve methodological approaches to environmental policy analysis, while the third examines a substantive approach amenable to a critical realist approach. This is not meant to be exhaustive but rather a limited articulation of the form in which a critical realist environmental policy analysis might be expressed, and offer concrete examples of how the admittedly vague philosophical tenets discussed above may impact the analyst's work.

\section{Interdisciplinarity}

One of the few concrete mandates to critical realist social science practitioners is to embrace interdisciplinary approaches to their work. The interdisciplinarity urged by critical realism is premised largely on its core principle of emergence; since phenomena emerge from a multiplicity of causal mechanisms across different strata of reality, understanding how these mechanisms interact requires cross-disciplinary understanding. The critical realist theorist Andrew Sayer (2000, p. 7) sees "[d]isciplinary parochialism . . . a recipe for reductionism, blinkered interpretations, and misattributions of causality." 
Under this tenet, neither physical and natural phenomena should be considered, or studied, as ontologically "flat" phenomena: just as the properties of water cannot be derived from the structure of hydrogen and oxygen atoms, the functioning of a banking system cannot be derived solely from the psychology of the bankers. Bank system functioning emerges out of a complex multiplicity of social and natural mechanisms, including banking laws, the workings of other parts of the economy, physical and infrastructure design, etc. Describing why that system functions the way it does may require analysis carried out through a number of disciplinary analyses, including economics, law, psychology, and engineering.

While calls for interdisciplinarity have become more frequent across both natural and social science fields, the environmental policy field in some ways has been long ahead of the game: the nature of environmental problems tends to require collaborative work between experts on various aspects of natural scientists such as chemists, toxicologists, and biologists. On the social science side, economists have also frequently collaborated on policy analyses, particularly when rule development requires economic evaluation, such as in cost-benefit analyses or economic feasibility determinations. From a critical realist perspective, interdisciplinarity has a deeper importance than simply collaboration. The "purely additive pooling of the results of the knowledge of the distinct mechanisms" (Bhaskar, 2010, p. 4) does not provide adequate tools to analyze emergent phenomena in open systems because of the complex interdependence of causal mechanisms. A cognitive understanding of how these mechanisms work together is required.

This is especially true for many of the complex systems environmental policy analysts study. For example, climate change implicates numerous disciplines and causal mechanisms, both natural, social, and hybrid. In examining the challenges posed by anthropogenic climate change, Bhaskar himself argues that the "interdisciplinary research worker [must have] a 
judicious combination of disciplinarity and interdisciplinarity in their education" to deal with things like climate change (2010, p. 20). Citing C.P. Snow's "two cultures" argument, Bhaskar (2010, p. 21) further suggests that the research worker aiming for interdisciplinary understanding should pick her subsidiary discipline from the other side of the natural or social science fields. As to the extent of training in that subsidiary field, Bhaskar cautions at the very least that members of interdisciplinarity teams must be able to "communicate effectively in crossdisciplinary understanding [which] will necessitate a form of education and continuing socialization of the interdisciplinary research worker, very different from that involved in orthodox multidisciplinarity." (Bhaskar, 1998, p. 5).

The level of understanding of that subsidiary field, of course, remains a question. Collins and Evans (2002, p. 254) usefully distinguish between "interactional experience" and “contributory experience." The former represents "enough expertise to interact interestingly with participants," while the latter represents "enough expertise to contribute to the science of the field being analysed." (Collins \& Evans, 2002, p. 254). This may offer a suitable goal for the interdisciplinary critical realist analyst as well; indeed, an intermediate level between "interactional" and "contributory" expertise may be a better target for analysts who must incorporate the work of specialists into their own decision-making. ${ }^{8}$

A related advantage offered by intense interdisciplinarity is that it can give the analyst a more accurate view of the current transitive state of the environmental science under dispute. As Sarewitz (2011) notes, scientific research prepared for policy-making is often done through consensus reports, with "[t]he commitment to consensus ... com[ing] at a high price: the

\footnotetext{
${ }^{8}$ Of course, this depends on the field; a low level of interactional experience may be the best a non-specialist policy analyst may hope for when looking at a field like say, quantum mechanics, but for most of the fields in which an environmental policy analyst encounters such as epidemiology or ecology a high level of interactional expertise is possible for the nonspecialist.
} 
elimination of proposals and alternatives that might be valuable for decision-makes dealing with complex problems." The problem is not limited to policymakers but also extends to natural scientists working in different fields. Collins and Evans (2002, p. 246) argue that scientists outside the "core" of practicing specialists in one field tend to see the "core's" field as operating with more certainty than the "core" recognizes, because like policymakers and the general public they tend to learn about that field from sources that "[i]nevitably ... condense and simplify." An interactional understanding not just of the abstract principles of such a field but also its practices, including how its practitioners evaluate and debate points of uncertainty or contention, can provide critical insights into environmental science, with direct policy implications.

\section{Problem Definition and Ontological Engagement}

Critical realism's focus on understanding a structured, differentiated reality; when using it to analyze environmental policy issues, questions of ontology can drive how environmental problems are defined at a fundamental level. For example, a recurring debate in environmental research is the extent to which "natural" domains can - and should - be distinguished from artificial ones. Philosophical approaches to examining nature and culture often fall between two diametrically opposite poles, holding either (1) a dualist "categorial opposition between Nature (body, animals, biological and physical conditions and contexts of life and so on) and Culture (meaning, subjectivity, identity, the human)" (Benton 2005, p. 137); or (2) a monist dissolution of the boundaries into "hybrid, chimeric, complex, and entangled" wholes (Castree \& MacMillan, 2001, p. 210).

A great deal of environmental social science over the past several years has focused on distinguishing (or breaking down distinctions between) "nature" and "culture," or more specifically the natural and built environments. Unsurprisingly, considering its focus on 
ontology, much critical realist discussions of environmental issues have therefore focused on the nature/society dichotomy (Forsyth, 2001). How environmental researchers approach that debate can have real-world policy implications. For example, from an environmental history perspective, conceptions of a strong nature-culture divide led to the preservation movement and the creation of nominally "pristine" parks and wilderness areas. More recent policy approaches that break down those sharp distinctions may be reflected in the use of ecosystem-based management approach to environmental management that examines the interaction between both human and non-human elements in an ecosystem.

Definitions of environmental degradation seem to be particularly problematic as a category. Fairhead and Leach (1998), for example, critiqued the orthodox definition of environmental degradation in the context of West African deforestation, showing that purported forest loss attributed to population growth and the breakdown of organized natural resource management actually misrepresented the landscape, which had actually seen forest growth over the relevant time. Examining that work and similar critiques of environmental degradation definitions, Forsyth (2001) offers an expressly critical realist approach to conceptions of degradation, arguing against "environmental orthodoxies" which he links to "historic scientific practice based on the search for positivist and universal laws" (Forsyth, 2001, p. 3). He argues that understanding degradation cannot be defined simply biophysically but also must explore how purportedly scientific laws relating to the environment reflect historic political and social relations (Forsyth, 2001). Going beyond an interpretivist deconstruction of such meanings, he argues for "reconstruct[ing] new and more effective science for environmental policy that is both biophysically more accurate than existing conceptions, and socially more just" (Forsyth 2001, 2). 
Similar definitional problems may arise in defining and acting on invasive species. Traditional scientific views of invasive species see them as a significant threat to "natural" landscapes, and seek to control that threat through measures such as border control of plant and animal species, ranging from requiring ships to discharge ballast water far from their destination ports, to tightly regulating which plants and animals can be transported through networks. Over the years, however, some researchers working in an interpretivist frame have criticized the concept of "invasive species" as largely a linguistic construction rooted in xenophobic fear of the other (Peretti, 1998; Raffles, 2011; Subramaniam, 2001).

Such conceptions of "invasive species," they argue, both feed on and feed into oppressive xenophobic views of immigration. Does focusing on the social use of invasive species this provide a good ontological base for policy prescriptions? To the discourse-focused academic, divorced from the extradiscursive reality of the invasive species' impact-at worst, they may see a slight increase in produce prices at the grocery for crops impacted by such species-such interpretation is easy. To the rural farmer who sees her crop destroyed and her livelihood threatened or destroyed by these species, such deconstruction does little; for example, in subSaharan Africa maize makes up the staple food for approximately half the population, a region where approximately 200 million people are chronically undernourished. Despite the critical importance of maize to some of the poorest communities in Africa, the region has significantly depressed maize yields largely due to invasive species like witchweed and the larger grain borer insect (e.g. Gressel et al., 2004). Critics of invasiveness as a discursive construct typically do not, of course, deny that individual species, including invasive ones, may require management. ${ }^{9}$ Their

\footnotetext{
${ }^{9}$ In a later work Raffles later did "[c]oncede[] a limited, strategic version of . . . relatively autonomous in their biophysicality ... nature," which he characterizes as existing "somewhere in the region of a critical realist approach to the non-human." (Raffles, 2002, p. 172).
} 
call for a more contextualized understanding that avoids general "covering laws" is convincingbut not necessarily to the extent that some wish to take it. Such overcontextualization may minimize the fact that invasive species do have a tendency to disrupt ecosystems specifically because they are from outside, i.e. they did not co-evolve with native species and the latter are thus less likely to have developed defensive or offensive capacities which would protect them from predation. Discursive purity may therefore come at the price of biophysical damage. As Margaret Archer puts it that "[t]he post-modern experience is not on globally for those needing bread not circuses and seeking freedom of expression not expressive freedom" (Archer 1998, p. 193). Along similar lines, Benton (2005, p. 142) criticizes the "comforting invention" of socially constructed nature, extrapolating such construction to an absurdist conclusion: "[f]ortunately for the indigenous peoples of the tropical moist forests, their 'nature' is a different one from that of the loggers and dam-builders: both can happily coexist in their incommensurable cultural universes (I don't think!).”

\section{Investigating Environmental Justice}

The third example I present involves the analysis of environmental inequity through an environmental justice paradigm. Traditional neopositivist approaches to environmental policy and governance tended to come from a utilitarian perspective, assuming environmental policy decisions were to be made in such a way so as to maximize overall benefits while reducing overall costs, without paying specific attention to who exactly enjoys those benefits and pays those costs-cost-benefit analysis is one manifestation of this. Over the past couple of decades, however, activists, academics, and policymakers have argued that this approach can be discriminatory towards communities that already suffer from the effects of other forms of social, 
geographical, and procedural inequities, particularly poor communities and communities of color.

In the United States this movement began in the early 1980s in response to a decision by the state of Georgia to situate a PCB disposal site in a predominately low-income, predominately African-American community (Brown 1995). Though the resulting protests were unsuccessful in stopping the disposal site, they did set off what quickly became known as the Environmental Justice movement, a social movement seeking to ensure "the fair treatment and meaningful involvement of all people regardless of race, color, national origin, or income with respect to the development, implementation, and enforcement of environmental laws, regulations, and policies" (U.S. Environmental Protection Agency, 2018). Though it started as an activist movement, environmental researchers subsequently created an academic field investigating environmental justice issues; most notably, the United Church of Christ's Commission for Racial Justice (which had held a leading role in the original Warren County demonstrations) commissioned a landmark report that found black, Hispanic, and Indian communities were more likely to live in the vicinity of toxic waste sites (Commission for Racial Justice, 1987).

Subsequent research in the United States has followed this template, focusing primarily on investigating spatial and temporal correlations between environmental hazards-often toxic waste sites-and demographic characteristics, typically race and ethnicity. However, this neopositivist, correlationist approach has proven problematic in establishing incidents of environmental discrimination. First, the results of spatial proximity analyses cannot show in themselves the causal mechanisms that led to the correlation between environmental hazards and specific ethnic or socioeconomic groups. This can have real-world impacts; for example, the United States Supreme Court has held that plaintiffs can only successfully prosecute a federal 
claim for racial discrimination against the government if they can show that the discrimination was intentional (Alexander v. Sandoval, 2001). In such a situation, merely showing that a toxic waste site had a disparate impact on African-Americans, for example, would not be sufficient to find relief under American civil rights laws.

Second, while spatial analyses can offer a snapshot - or a series of snapshots - of distributions of social and environmental phenomena, they are heavily dependent on the assumptions built into geographical information models, particularly scale. One common manifestation of this is what geographers refer to the Modifiable Areal Unit Problem, which occurs when point data like toxic sites are aggregated into values that apply to a certain areal unit (e.g., toxic waste sites per county) (Openshaw, 1984). Spatial correlations that exist when the areal unit used is the county may weaken, strengthen, or vanish when a larger or smaller areal unit is used. Thus, when Anderton, Anderson, Oakes and Fraser (1994, p. 243) examined the demographics of toxic waste sites in the United States but using smaller census tract areal units instead of the zip code areal units used by the United Church of Christ study, they found "almost no support for the general claim of environmental inequity." A critical realist approach to environmental justice, therefore, might focus less on establishing conjunctions of environmental hazards and the proximity of poor communities and communities of color through correlation studies, and focus instead on the causal mechanisms and the unique historical characteristics of potential sites of inequity.

One possible template for this kind of critical realist environmental justice research could be the Michigan Civil Rights Commission's report on the Flint, Michigan water crisis of 20142016. Lack of proper oversight and financial problems in the city of Flint led to a horrific lead poisoning epidemic when municipal authorities attempted to switch the city's water supply to a 
cheaper source. During the change, the city used the local Flint River as a temporary supply of water, but the high acidity of the water leached lead from water pipes, leading to widespread lead poisoning. In the aftermath of the crisis, the Michigan Civil Rights Commission, an independent government agency tasked with investigating discrimination in the state, conducted a lengthy study of what caused the crisis. Though the Commission examined the immediate proximate cause of the crisis, and who it affected, they also examined the complex history of Flint and the United States. The Commission concluded that the underlying issue behind the water crisis was a historical and systemic racial segregation and discrimination of the African-American community over more than a hundred years (MCRC 2017, p. 2). Though the Commission did not take an expressly critical realist approach, the language they use shows a similar acceptance of complex causal mechanisms: "Today's disparities ... are often the result of the complicated relationship between numerous factors, policies and causes that interconnect to produce and reproduce ... racial disparities and unjust harms" (MCRC, 2017, p. 19).

\section{Conclusion}

How do we make decisions when creating policy interventions to regulate human interactions with the environment? And how should we? Any attempt to examine environmental problems and prescribe social institutions to address them requires some epistemological assumptions as to how we can obtain knowledge of our objects of study and the intrinsic constraints on humans' ability to obtain that knowledge. Analyzing those assumptions requires taking a step back from methodology to look at the philosophical foundations of what those methods can tell us, a step that policy analysts often do not take.

Modern environmental policy analysis and development has moved towards a deeper and more critical approach to understanding environmental problems that implicate both natural and 
social systems. Critical realism may offer analysts a philosophically coherent and potentially useful epistemological foundation in support of this goal. Accepting ontological realism but epistemological fallibilistic-that there is a real world out there independent of our conception of it, but that our explanations of it will always be provisional and subject to revision-critical realism mandates an interdisciplinary approach, a skepticism of "covering laws," and an openness to the complexity and interdependence of social-ecological systems. 


\section{$\underline{\text { References }}$}

Amy, D. J. (1984). Why policy analysis and ethics are incompatible. Journal of Policy Analysis and Management, 3(4), 573-591. https://doi.org/10.1002/pam.4050030407

Anderton, D. L., Anderson, A. B., Oakes, J. M., \& Fraser, M. R. (1994). Environmental equity: The demographics of dumping. Demography, 31(2), 229-248.

Archer, M. (2001). Introduction: Realism in the Social Sciences. In M. Archer, R. Bhaskar, A. Collier, T. Lawson, \& A. Norrie (Eds.), Critical Realism: Essential Readings. New York: Routledge.

Archer, M., Bhaskar, R., Collier, A., Lawson, T., \& Norrie, A. (Eds.). (2001). Critical realism: Essential readings. New York: Routledge. Retrieved from http://proquest.umi.com/pqdweb/?did=140305971\&Fmt=7\&clientId=46781\&RQT=309\&V Name $=$ PQD

Ascher, W., Steelman, T. A., \& Healy, R. G. (2010). Knowledge and environmental policy: Reimagining the boundaries of science and politics. Cambridge, Mass.: MIT Press.

Bhaskar, R. (2008). A realist theory of science (2d ed.). Oxon, UK: Routledge.

Bhaskar, R. (2015). The possibility of naturalism: A philosophical critique of the contemporary human sciences. (EBSCOhost, Ed.) (Fourth edi). Abingdon, Oxon : Routledge.

Bhaskar, R., Frank, C., Hoyer, K. G., Naess, P., \& Parker, J. (Eds.). (2010). Interdisciplinarity and climate change. New York: Routledge.

Boguslaw, R. (1979). Postpositivism and the dilemmas of social planning. Society, 16, 40-44.

Brown, P. (1995). Race, class and environmental health. Environmental Research, (65), 15-30.

Cairney, P. (2013). How can policy theory have an impact on policy making? International Conference on Public Policy, (June).

Carolan, M. S. (2005). Society, biology, and ecology: Bringing nature back into sociology's disciplinary narrative through critical realism. Organization and Environment, 18(4), 393 421. https://doi.org/10.1177/1086026605281697

Collier, A. (1994). Critical realism: An introduction to Roy Bhaskar's philosophy (First). London, UK: Verso.

Collins, A. H. M., \& Evans, R. (2002). The third wave of science studies: Studies of expertise and experience. Social Studies of Science, 32(2), 235-296. 
Commission for Racial Justice (CRJ). (1987). Toxic wastes and race in the United States.

Retrieved from https://www.nrc.gov/docs/ML1310/ML13109A339.pdf

Comte, A. (1865). A general view of positivism. London: Trubner and Co.

Durning, D. (1999). The transition from traditional to postpositivist policy analysis: A role for QMethodology. Journal of Policy Analysis and Management, 18(3), 389-410.

EPA. (2018). Environmental Justice. Retrieved from https://www.epa.gov/environmentaljustice

Fischer, F., \& Gottweis, H. (2013). The argumentative turn in public policy revisited: Twenty years later. Critical Policy Studies, 7(4), 425-433.

Fischer, F. (2003). Reframing public policy. Policy Analysis, 1(4), 2003-2011.

Fischer, F. (1998). Beyond empiricism: Policy inquiry in post positivist perspective. Policy Studies Journal, 26(1), 129-146.

Forsyth, T. (2001). Critical realism and political ecology. In After postmodernism: Critical realism? (pp. 146-154).

Gorski, P. S. (2013). "What is critical realism? And why should you care?" Contemporary Sociology: A Journal of Reviews, 42(5), 658-670.

Guston, D. (2013). Democratizing science. In G. P. Zachary (Ed.), The rightful place of science: Politics (pp. 39-45). Tempe, AZ: Consortium for Science, Policy, \& Outcomes.

Hacking, I. (1983). Representing and intervening: Introductory topics in the philosophy of natural science. Cambridge, UK: Cambridge University Press.

Hawkesworth, M. E. (1988). Theoretical Issues in Policy Analysis. Albany, NY: State University of New York Press.

House, P. W., \& Shull, R. D. (1991). The practice of policy analysis: Forty years of art \& technology. Washington, D.C.: The Compass Press.

Hume, D. (1738). A treatise of human nature: Volume 1. (D. F. Norton \& M. J. Norton, Eds.). Oxford, UK: Clarendon.

Hume, D. (1748). Philosophical essays concerning human understanding. London: A. Millar.

Jasanoff, S. (1990). The fifth branch: Science advisers as policymakers (2d ed.). Cambridge, MA: Harvard University Press.

Kahneman, D. (2011). Thinking, fast and slow. New York: Farrar, Straus and Giroux. 
Kuhn, T. (2012). The structure of scientific revolutions (4th ed.). Chicago, IL: The University of Chicago Press.

Lasswell, H. D. (1971). A Pre-View of Policy Sciences. The American Political Science Review, 67(4), 1-173. https://doi.org/ISBN 0444001123

Latour, B. (1993). We have never been modern. Cambridge, Mass.: Harvard University Press.

Layzer, J. A. (2012). Open for business: Conservatives' opposition to environmental regulation. Cambridge, MA: The MIT Press.

Michigan Civil Rights Commission (MCRC). (2017). The Flint Water crisis: Systemic racism through the lens of Flint, 138.

Mintz, J. (2012). Enforcement at the EPA: High stakes and hard hoices (Rev. ed.). Austin, TX: University of Texas Press.

Openshaw, S. (1984). Ecological fallacies and the analysis of areal census data. Environment and Planning A, 16, 17-31.

Peretti, J. H. (1998). Nativism and Nature: Rethinking Biological Invasion. Environmental Values, 7(2), 183-192.

Popper, K. (1959). The logic of scientific discovery. London: Routledge.

Putnam, H. (1982). Three kinds of scientific realism. The Philosophical Quarterly, 32(128), 195-200.

Rabinow, P., \& Sullivan, W. M. (1979). Interpretive social science: A reader. Los Angeles: University of California Press.

Raffles, H. (2002). In Amazonia : a natural history. Princeton, N.J. : Princeton University Press.

Raffles, H. (2011, April 7). Mother nature's melting pot. The New York Times.

Rittel, H. W. J., \& Webber, M. M. (1973). Dilemmas in a general theory of planning. Policy Sciences, 4(2), 155-169.

Sarewitz, D. (2016). Foreword. In A. Benessia, S. Funtowicz, M. Giampietro, A. Saltelli, Â. G. Pereira, J. R. Ravetz, ... J. P. van der Sluuijs (Eds.), The rightful place of science: Science on the verge (pp. iii-vii). Tempe, AZ: Consortium for Science, Policy, \& Outcomes.

Sarewitz, D. (2000). Science and environmental policy: An excess of objectivity. In Earth Matters: The Earth Sciences, Philosophy, and the Claims of Community (pp. 79-98). Upper Saddle River, NJ: Prentice-Hall. 
Sayer, A. (2000). Realism and social science. Thousand Oaks, CA: SAGE Publications.

Sismondo, S. (2008). Science and Technology Studies and an engaged program. In E. J. Hackett, O. Amsterdamska, M. Lynch, \& J. Wajcman (Eds.), The handbook of Science and Technology Studies (3rd ed., pp. 13-31). Cambridge, MA: The MIT Press.

Sokal, A., \& Bricmont, J. (1997). Fashionable nonsense. New York: Picador USA.

Stone, D. (1997). Policy paradox: The art of political decision making. New York: W.W. Norton.

Subramaniam, B. (2001). The Aliens Have Landed! Reflections on the Rhetoric of Biological Invasions. Meridians, 2(1), 26-40.

Verstegen, I. (2009). Maurice Mandelbaum and American critical realism. Taylor \& Francis.

Waldo, D. (2006). The administrative state: A study of the political theory of American public administration (Rev. ed.). New Brunswick, NJ: Transaction Publishers.

Weinberg, A. M. (1974). Science and trans-science. Minerva, 10(2), 209-222.

Yanow, D. (2000). Conducting interpretive policy analysis. Conducting interpretive data analysis. Thousand Oaks, CA: SAGE Publications. 